Original Article

\title{
Homeopathic pathogenetic trial of Plumbum metallicum: the complete 2000 trial with a synthesis of the original 1828 trial
}

\author{
Andrea Maria Signorini, Christa Pichler \\ FIAMO, Scientific Department, Italy
}

\begin{abstract}
Background: in a previous paper we reported the statistical analysis and other distribution data of a homeopathic pathogenetic trial (HPT) of Plumbum metallicum $30 \mathrm{cH}$ carried out by our group. However, at that time we did not report the resulting pure materia medica, i.e., the totality of symptoms elicited by the tested medicine on healthy volunteers. Aim: to communicate to the homeopathic community the full record of symptoms collected in our HPT of Plb. Methods: methods to collect and select symptoms have been reported in the previous paper. In synthesis were excluded all previous common symptoms of volunteers, even with slight differences, and selected only those that were really unknown, never seen, unusual or very strange for the prover. In this paper special emphasis was given to new symptoms as well as unusual or repeated dreams, while in the previous paper special emphasis was given to repeated and crossed symptoms. Results: symptoms are reported in their chronological order of appearance in each volunteer. 37 new symptoms were found, useful to update Homeopathic Repertories. It is also included a synthesis of the original HPT of Plb carried out in 1828 in order to make available the full experimental materia medica currently existing. Conclusions: the new HPT, besides widening the pathogenetic picture of $\mathrm{Plb}$ (skin and mucosae symptoms), also allowed us to give new and deeper meanings to some of the symptoms reported in the original trial, such as Anxiety, Activity, Depression, Slowness, Gastro-oesophageal problems, Colitis. The dreams complete the remedy image, mainly in work, religion and sexual themes. Up to the present time there is no peer-reviewed publication devoted to HPTs. For this reason, researchers are compelled to publish HPTs as private editions. This results in poor control of the quality of publications and a lack of standards on how to present the results of HPTs.
\end{abstract}

Key words: Homeopathic pathogenetic trials, Plumbum metallicum, retrial, clinical indications.

\section{Introduction}

The homeopathic pathogenetic trial (HPT) of Plumbum metallicum 30cH carried out by our group in 2000 was the first double-blind, placebo-controlled trial to apply the 3-arm design to HPTs, also known as provings. This involves 2 different verum groups, in this case Piper methysticum and Plb, and 1 placebo group. In this study, volunteers took the medicines frequently until the appearance of perceivable symptoms, as indicated by Hahnemann in his guidelines for the performance of HPTs [Organon, see §105-140). Moreover, for this study we chose previously tested substances (retrial), one with good-quality ( $P l b)$ and another with poor-quality (Pip-m) trials. This allowed us to compare the symptoms obtained in our study with the previous ones, especially as to establish repeatability, which was one of the goals of our HPT.

Our study was carried out in 2000 in 7 homeopathic schools associated with FIAMO (Federazione Italiana delle Associazioni e dei Medici Omeopati) and a part of the results was reported in 2005 [1]. There we only described the "repeated" and "crossed" symptoms, namely, the symptoms repeating in a single volunteer at least 3 times in at least 2 different days, and the symptoms appearing in at least 2 different volunteers, 
respectively. Other distribution data were also reported: 1) symptoms agreeing with the ones reported in the original HPT of Plb, published in 1828 by German homeopaths Hartlaub and Trinks [2]; 2) distribution of symptoms in Kent's homeopathic repertory (K) and/or repertory Synthesis 9.1 (S) [3,4]; 3) statistical analysis of the data reported by the 2 verum and the 1 placebo groups (we reported statistical differences between Plumbum and placebo groups, but not between Piper group and placebo). It is worth to mention that, at that time, Synthesis 8.0 was the latest edition of that work [5].

When analyzing the written records of the volunteers, we observed that they had filled in the trial diaries in 2 different ways: 1) what we called "synthetic journals", i.e. exclusive report of the unusual, strange and/or peculiar symptoms; and 2) "descriptive journals", which besides the unusual symptoms, also reported in detail the volunteer's day of life including their thoughts.

We describe below the symptoms exhibited by the 7 volunteers who took $P l b$ and completed the trial. Each volunteer is identified by a code number, which is followed by the day on which each symptom appeared (p). Thus, e.g., "6-5p" means a symptom reported by volunteer number 6 on the $5^{\text {th }}$ day of the trial.

The symptoms obtained in our trial (IT) are compared, here as in the previous trial, with 2 previously existent sources: 1) the original 1828 HPT (GT), the corresponding (concordant) symptoms appear written in bold in the results of our trial. The English translation of GT symptoms appears at the end of each IT journal, signalled with the number attributed by the original authors (e.g., GT334 is symptom 334 in GT); 2) homeopathic repertories $\mathrm{K}$ and $\mathrm{S}$, indicating the corresponding page in each one (e.g., K59a means Kent's repertory, page 59 , first column of the 2 -column edition).

Reported events lasting 2 or more days were counted, correspondingly, as 2 or more events. Symbol (!) represents a new symptom or a new modality. At the end of each diary, doubtful symptoms are reported when they were present. Table 1 describes the characteristics of the 2000 trial (IT); Table 2, the new symptoms reported in the 2000 trial (IT); Table 3, the key-symptoms of Plb in both the 1828 (GT) and 2000 (IT) trials. The Appendix presents a synthesis of the GT symptoms, noted with the number attributed by its original authors.

Abbreviations: IT $=2000$ trial, the number after IT represents the volunteer's code; GT $=1828$ trial; $p=$ trial day; K= Kent's Repertory, $\mathrm{S}=$ Synthesis 8.0 - the number after K or S is the page number in which the symptom is found; $\mathrm{PN}=$ volunteer's note; $\mathrm{SN}=$ supervisor's note. Abbreviations of German observers in GT: $\mathrm{Ng}=$ Nenning, $\mathrm{Hg}=$ Hering, Ts= Trinks, $\mathrm{Hb}=$ Hartlaub, Bthm= Bethmann; (!)= new symptom or new modality.

Table 1: Characteristics of the $2000 \mathrm{HPT}$

Country: Italy

Year of trial: 2000

Dilution: $30 \mathrm{cH}$, liquid

Scheme of use: 5 drops, 4 times daily

Number of participating homeopathic schools: 7

Method: classical, 3-arms, double-blinding, placebo-controlled

Statistics: Kruskal-Wallis test for non-parametric data

First general publication (without the pure materia medica): Homeopathy (2005) 94, 164-174

Groups and size: 7 Plb. 11 placebo, 13 Pip-m., total 31.

Principal Investigator: Andrea Signorini, via Molinara 14, 37135 Verona; tel +39.045.581141, cell: +39.335.1707251; e-mail: asignorini@tiscali.it.

Principal Supervisors: A Lubrano, G Manuele, G Fagone, C Vittorini, P Vianello, A Rebuffi, T Frongia, 
Manufacturer and sponsor of the trial (excluding publications): CE.M.O.N. Homeopathic Laboratory, via E. Fermi 4, 80028, Grumo Nevano (Naples) - Italy. Tel +39.081.2482376; www.cemon.eu; e-mail: info@cemon.eu. Pharmaceutical Director: Dr. Luca Martirani, 1.martirani@cemon.eu.

\section{Experimental pure materia medica}

\section{Prover 6 - IT6}

3 events, 6 symptoms, 2 concordant symptoms - descriptive diary.

PN: I noticed that sleep was better than usual and was enriched by dreams that normally I do not remember (see Dreams). SN: during the next week (after the intake) sleep was not continuous, he awakened during the night as it was usual before.

6-1p: In the evening, after dinner (cheese and beans) I have a slight headache, as if somebody was pressing my forehead (K192b), I wrinkle my forehead (K396b, face; new modalization: Forehead) (!).

6-5p: At midnight (before going to sleep), I ate a sandwich: I was very hungry (!) (2 new modalities: during the night and association with sleepiness, see Table 2); I was not able to speak anymore (K 420 a) and I was sleepy.

6-6p: Evening, great craving for ice-cream, therefore I go out to buy an ice-cream with cream (it is a strange desire, unusual) (!).

1. GT 60: Pressure in the forehead, more externally (the second evening). (Ng).

2.GT 255: Feeling of hunger and nausea, evening before going to sleep ( $\left.6^{\text {th }} d.\right)(T s$.

\section{Doubtful Symptoms}

6-1p: Night, my face is swollen (K392b)

6-7p: Evening, I'm studying; I'm able to learn and to memorize what I read (symptom selected by supervisor, but excluded because it is an amelioration).

\section{Prover 21 - IT21}

16 events, 37 symptoms, 4 concordant, 2 repeated symptoms - synthetic diary

21-2p: In the morning, a small ulcer appeared (!) (lasted for 1 day), not discharging, on the root of the glans, 2 $\mathrm{mm}$ diameter, not painful, red on the bottom and with excoriations at the margins (S1087b).

21-2p: Night, appearance of itching exanthematic eruptions (K1314a, itching) (S1859b, redness), in the region of both calves, more on the left, ameliorating by scratching (K1328b). Started $1 / 2 \mathrm{~h}$. after $4^{\text {th }}$ intake, lasting for 6 days. On the $5^{\text {th }}$ and $6^{\text {th }}$ day appearance of a green-bluish halo (K $\left.982 \mathrm{~b}\right)$.

21-3:4p: Night, disturbed sleep, (K1235a) waking every 2 hours. Night perspiration (K1294b) on the nape and neck. 
21-4p: In the morning, appearance of an itching excoriation on the right side of the scrotum (S1087b), ameliorated by scratching (K1328b) and cold water (!) (for 4 days), it then becomes an itching desquamation (K1311a). Indented tongue (K406a), slightly white-coloured (K402a), with a crack at the center (K399b). Dryness of the conjunctiva (K238a).

21-4:5p: Sleep interrupted by repeated awakenings after 4.00 a.m. (K1255a).

21-5p: In the morning, sudden gastric pain (K511a) with massive nausea (K504b), that disappears spontaneously after $5 \mathrm{~min}$. (31/2 h. after $1^{\text {st }}$ intake).

21-6p: At 5 a.m., sudden drawing pain (K182a), in the left parietal region of the head (K167a), which disappeared after a few seconds.

21-6p: Night, before sleeping, reappearance of a sudden drawing pain (K182a) in the left parietal region of the head (K167a), also this time for a few seconds.

1. GT 585: After perspiration, excoriation of the skin of the scrotum and thigh when they come in contact. (Hg).

2. GT 973: He awakens at 4.00 in the morning (with troubles in the limbs)(3th $d).(\mathrm{Ng})$.

3. GT 271: Nausea and feeling like vomiting (after 2 h.), (passing)-fleeting sensation (Ng).

4. GT 49: Slight headache, in the anterior part of the left parietal bone (a. $1 \mathrm{~h}).(\mathrm{Ng})$.

Prover 24 -IT24

31 events, 47 symptoms, 9 concordant, 9 repeated - descriptive diary

24-1p: In the morning, I feel that the substance is active, because I feel an emotional reaction, not disagreeable, as if the heart would be more charged (during the first hours).

24-1p: In the morning, I make mistakes in writing, misplacing letters. Example: "Teh" instead of "The", "inscead" in place of "instead" (noticed for 9 hours) (!).

24-1p: In the afternoon, I feel a little tense (NS: the volunteer describes this sensation as a desire for activity) (K4a, S3b).

24-1p: In the afternoon, I cannot relax very well in bed (K1235a), as if I couldn't release some tension; this usually does not happen (K4a, K1406b, K1407a: Anxiety, Tension, internally and Tension, muscles).

24-1p: In the afternoon, I feel myself full (K1350b) in the upper part (K110a), that is, in the superior part of the body. A slight sensation of dilatation (K828b) and bursting in the heart (!) and the head (K110a).

24-1p: Evening, I feel that the remedy sharpens my tendency to be in step with my patients' problems. I feel a great desire to help them and protect them (NP: it was different from sympathy).

24-1p: Night, general tension (K5a, Anxiety, night), not disagreeable, but usually I'm more relaxed inside myself.

24-2p: Morning, I have good "internalized" energies that are growing from inside me, in particular from my heart; I feel the drive of the substance that seems to be active. I feel a certain positive tension in the region 
of the heart (K824a Apprehension, Heart, region of). I only worry that if this emotional tension remains active it might exhaust my heart or me too much (S121a, Fear, heart, disease of the).

24-2p: Morning, writing mistake! (NS: "tesnion" in place of "tension")

24-2p: Afternoon, beyond troubles and moroseness (K68a), I feel driven by strength to go on without wasting my time in frills (K56a).

24-3p: Afternoon, weakness in my legs (K1228a, K1231a) and extremities (K1224b, K1226a, K1228a).

24-3p: Evening, feeling of slight congestion in the occiput and the nape (K110a, K127a).

24-3p: Night, I feel tense inside, even when being tired (K5a).

24-3p: Writing mistakes ("insite" instead of "inside").

24-3p: Until 1 a.m. the sensation of weakness in my legs (K1231a) continues and reminds me of a similar one I had when I was a teenager.

24-4p: Morning, disposition to help, sensibility to understand and to support (NP: but it is not sympathy); as if a solar male force was taking place, able to think in terms of clarity, distinction, plans, autonomy, dynamism (S189b).

24-4p: Morning, upon waking up, I don't feel very fit, I take a lot of time to fire on all cylinders and to reach merely tepid spirits (K1414b) (to have sufficient good disposition).

24-4p: Morning, I would like to rest some more, but I have a certain drive towards action, to feel engaged (K56a). It is a calm drive.

24-4p: Morning, I feel myself a little full (K1350b) in the chest and the head (K110a). Energy seems driven upwards (pushed towards the higher area of mind and soul), sexuality does not live on desire (K711b, S1102a, S1155a). It is as if I have an energetic axis in my backbone, especially at the lumbar level, which supports, controls and drives (NP: it is as if I have a wire which sustains and holds me upright, a sensation of verticality, of going upwards) (!). But there is some weakness in the extremities (K1228a) and the backbone drive sometimes is felt as tension.

24-4p: Morning, immediately after taking the remedy: increase of the tension in the head (K112a) clearer than in the previous days, especially in the anterior part of the head (K113a) with a sense of slight tension in the jaws (K379a).

24-4p: Morning, the tension in the head (K112a) comes with a very slight sensation of nausea (K504b); the eyes moisten up, with a slight feeling of congestion (K110a), which grips the head, mainly in the cortical (or meningeal) area of the cerebral mass; in short, in the more external areas (K128a, Inflammation meninges).

24-4p: Evening, immediately after taking the remedy, I feel a sensation of weakness in the extremities as if a difficulty to move (K1224b, K1228b-after walking, K1231b-walking, while, K1417a-slight exertion, K1418a-motion).

24-5p: Morning, immediately after taking the remedy, I feel sensitive to a draft of air (NS: more clearly than usual). The time passes and I do not realize it, as if I was slower to do everything (S220a). Less speed...

24-5p: Morning, it seems that the dimension of this proving would be one of interiorizing (S153a) ... 
24-5p: Morning, I am surprised by a certain calm, I feel a slight sensation that looks like sadness (K75b)... but it is only potential, because a positive drive to engage stays on (K56a).

24-5p: Evening, I avoid going out. I feel I have a flu, some cough, some catarrh. I feel cold even if it is not cold at all (K1367a). I put on a very heavy sweater and I start sweating inside. Perspiration is oilier than usual! (S1835b). I also close the windows to avoid draughts (!) (New, Air- draft). Then I feel that heat improves. [Onset and duration of the symptom (K1259b, CHILL-Coldness-morning continuing ... until evening)].

24-6p: Morning, again the sensation and ability to stay with my patient (see $24-1 \mathrm{p}$ and $4 \mathrm{p}$ ).

24-6p: Morning, I do not take the remedy, because I'm afraid not to be able to work. Weariness is strong (K1421a). But the sweating and the heat I love have helped me.

24-6p: Sensitivity to draught of air.

24-7p: Morning. Bad day. Great exhaustion. I do not have energy (diphase action: notice good energy in days $1 \mathrm{p}-5 \mathrm{p}$ and prostration in days $5 \mathrm{p}-7 \mathrm{p}$ ). No will to take the remedy and to write the journal, I do not know if it is placebo or active substance, but the journal is one more task [to accomplish].

24-7p: After the remedy I feel again very slight symptoms of flu. Sensitivity to draught of air. Weariness (K1421a) but sensation of tension (K4a).

1. GT 688: Worry, anxious for the heart. (after $1 / 2 h$.) (Ng)

2. GT 37: Extremely active, absorbed in work (knitting), thoughtful. In the afternoon (Ng).

3. GT 831: Weakness in the legs in the afternoon. (Ng). GT 832. Loss of strength in the muscular mass of the legs, while walking ( $1^{\text {th }}$ d.) $(H b)$.

4. GT 55: Feeling of heaviness in the occiput, as if it was increased in weight (Ts).

5. GT 58: Feeling of pressure beneath the skull as from blood rushing to the head. (Ts).

6. GT 833: Fatigue in the knees ascending stairs (1th d.) (Hg). GT 835 Morning upon rising from bed, weariness in hands and legs is so much that he could hardly walk. GT 838: Unusually tired and weak after motion. (Hg). GT 840 Easy weariness after walking.

7. GT 991: Very cold from morning till afternoon (Hg).GT 993. Feeling of cold, walking in the room (Ng).

8. GT 150: The skin of the face is oily, shiny and greasy, when touching it (Hg).

9..GT 858: Weariness, weakness, drowsiness and pains truly oppose the state of well-being perceived during the first days, which was exceptionally pleasant. During the first phase, the weather was wet and cold, while during the second one it was a very pleasant spring weather $(\mathrm{Hg})$.

\section{Doubtful Symptoms}

24-1p: About 3 p.m. blood pressure (S1971a) arose to 150/110 upon first measurement and to 130/95 upon the second. I feel some digestive problems, sour regurgitations (K496b), rumbling and abdominal distension (they were previously present except sour regurgitation) 
24-2p: Emissions of a lot of flatus, offensive, but not too much (fermentation more than putrefaction). Flatus is hot (K618a).

24-2p: I feel supported by a good energy, even if last night I did not sleep very well.

24-2p: I notice I urinate a little more frequently, urine with a stronger smell, not burning, not abundant (just happened). A little burning on the tongue after taking the remedy (I do not know if important?).

24-3p: Blood pressure is: 130/100!

24-4p: I wake up in the night after sleeping 3 hours, but weariness does not cease. Blood pressure is 130/90.

24-4p: My abdomen is distended and digestion is a little blocked (S790a). I had to write the journal but I do not like to do it (other 3 times).

24-5p: I notice that in other periods, weakness and weariness could have generated some irritability, impatience with the traffic or at the phone, but I have a certain calm (K89a).

24-7p: Blood pressure seems high: 140/100, then, after a nap 130/90.

\section{Prover 39 - IT39}

\section{9 events, 21 symptoms, 3 concordant, 2 repeated - synthetic diary}

39-2p: I woke up early at 6.30 a.m. (S1743b) a little nervous (similar: K58a). Slight vertigo (K96a) [ndP: when he woke up, for 2-3 sec without other symptoms (immediately after intake)]

4p: Increase of intake from 4 to 6 doses per day.

39-4p: Morning at 6.00, I have slept badly (K1235a), I woke up early, about 4.30-5.00 (K1255a) with a sensation of tension (K1406b, K56a: Industrious, see below) (New modality: on walking) (!).

[NP: this tension felt as if I had to think: "ready to go". It was not a slow awakening, but I felt immediately ready for work. It was a constructive tension, but it was enervating. I felt more active than usual (S3b, K56a), hyperactive. My wife instead found me less irritable, calmer and less reactive (K89a).]

39-4p: Morning, abdominal rumbling (K600b), distension (K544b), pain agg. touch.

39-4p: Evening, I feel like pin-pricks (NP: itching, not redness, scratching ameliorates) (K1328b, K1329a, stinging)(New:Prickling) (!) all over the body, they disappear then reappear in other areas (!); they are not painful but troublesome like itching. I experienced this some years ago when I ate many eggs for 5 days.

39-5p: Morning at 6.00, I slept badly (K1235a); I woke up early (S1743b), I feel myself more excited (S107b) in my deeper levels (R: he woke up early, unrefreshed and nervous, see note $4 \mathrm{p}$ ).

39-5p: Strong desire for ice-cream (!); very thirsty (K527b, K529a) - only today.

z39-6p: Morning, I slept, but I woke up early (S1743b) with sensation of tension (K4a) (see note 4p).

39-6p: Evening, reappearance of sensation of diffuse pin-pricks (S1329a). 
39-7p: Morning at 5.00. Woke up early (S1743b) with sensation of tension (K4a) (see note 4p).

1. GT 973: He awakes in the morning at 4 (Ng).

2. GT 37: Extremely active, absorbed in work (knitting), thoughtful. In the afternoon (Ng).

3. GT 149: Slight pin-pricks, here and there, in the skin of the face $(\mathrm{Hb})$.

\section{Prover 42 - IT42}

\section{9 events, 11 symptoms, 2 concordant - synthetic diary}

42-1p: Afternoon, right after the second remedy intake, a slight bothersome feeling in the mucous membrane of the lower lip (K383b) (at the edge with the outer lip), almost completely to the left, with a sour metallic taste (K424b) (S700a) (immediately after the remedy).

42-1p: Evening, the bothersome feeling in the mucous membrane of the lower lip (K383b) persists on the left and the right sides with an area of intact mucous membrane between them. The area corresponds to the fangs and lateral incisors. It looks like a little strip of shrivelled mucous membrane (S688a), as if it was chapped with colour irregularities.

42-1p: Constipation (K606b).

42-2p: Brushing my teeth, more bleeding (K398a).

42-3p: Occasionally, itching on the left nipple (K837a) (!).

42-4p: Evening, slight and fleeting sensation of giddiness (K96a) during dinner upon rising up from the chair (!), leaning forwards in the direction of my son, with instant recovery without consequences.

42-5p: Night, in the dark (!), with closed eyes, after having urinated and gone back to bed, sensation as if seeing a light bright spot before my eyes (K275a, Colors before the eyes, yellow, spots).

42-5p: Tendency to constipation (K606b).

42-6p: Morning, sensation of a bright spot before my eyes for some minutes (K275a).

1. GT 214: Sour and sulphurous taste deeply in the throat - after a quarter of an hour and after 2 hours and a half $(\mathrm{Ng})$.

2. GT 164: The lips peel daily, without pain, and without perceivable dryness (Hg).

\section{Doubtful Symptoms}

42-3p: Tendency to constipation (1).

42-4p: Constipation (1).

42-4p: Writing the journal, very slight sensation, almost imperceptible, of vertigo, sitting on my bed. 
42-5p: Decrease of the ever present itch and eczema on the right foot and right hand (ameliorated).

42-5p: More tendency to depression and irritability (aggravated, not selected).

42-6p: Tendency to constipation (1).

42-7p: Tendency to constipation (stool not abundant and harder) (1).

Prover 45 - IT45

33 events, 48 symptoms, 5 concordant, 7 repeated - descriptive diary

45-1p: Noon, I feel some cramps in the stomach (K517b). I crave for dry things, a sandwich, a biscuit, also to absorb the abundant salivation (K484a, 485b, and 486b). I feel the tongue like thickened (!).

45-1p: Afternoon, I feel a thick coating on the tongue (S670b).

45-1p: Evening, the cramping stomach pain persists. It is like a hand pressing and griping, strongly (K $517 \mathrm{~b})$.

45-2p: Morning, I feel slight spasms in the stomach (K517b).

45-2p: Noon, riding the car I felt first formication in the left foot and then numbness (K1040b, K1042b), I did not feel it from the ankle downward, I had not sensibility for the accelerator pedal so I had to stop the car, I had to massage it and then I drove without difficulty. Never happened before.

45-2p: Afternoon, after the remedy, I am bathed in sweat (S1836a), especially on the face (S635b) and neck (!), it is strange because usually I sweat in the axilla (armpit).

45-2p: Evening, I feel the tongue rough (!), rasping when it touches the palate.

45-3p: Morning at 6.00, I woke up spontaneously (S1743b), sleep was not as usual, as if I had slept all night like semi-conscious (!), nevertheless I feel myself restored.

45-3p: Noon, it bothers me to feel the tongue so rasping (!) when touching the palate.

45-4p: Morning at 6.00 (S1743b), I didn't sleep, in the sense that I was always semi-conscious (!).

45-4p: Night, omission of words (!) ("news of the death .. my friend", over the line: "of the wife of")

45-5p: Morning at 6.00, this morning I woke up spontaneously and early (S1743b). Sleep is not deep, always in a state of semi-consciousness (!): as if I was conscious and awake while sleeping.

45-5p: Noon, I feel cramps in the stomach (K517b) as if a hand would open and then grip the stomach.

45-5p: Afternoon, I am very annoyed because I notice mistakes in writing, in the sense that I omit (!) or I am wrong when writing words, and in addition to the irritation due to this, I am worried. Never happened before! (NS: it was as if ideas were quicker than writing, so it was difficult to fit them together) (!).

45-5p: Evening, I feel the tongue as if scraping (!) the palate.

45-6p: Even tonight sleep is semi-conscious (!). I woke up really early: at 6.00 (S1743b). 
45-6p: I feel a kind of impatience in my legs, I cannot stay in my seat, it is as if a subtle but troublesome trembling went all along the limb, proceeding from the hip and increasing from the knee downwards (K1213b, K1214a).

45-7p: Morning, I woke up early, even this night (S1743b) sleep was semi-conscious (!). I woke up really early at 6.00 (S1743). At $3 \mathrm{am}$. I had to urinate, and then sleeping again was difficult.

45-7p: Morning, even if I did not sleep very well I do not suffer from the lack of rest, but it is as if I would feel in alert, alarm, as if something could suddenly happen to me (S120b).

45-7p: Morning, I have pain in the stomach, I have cramps (this makes sadness worse) (K517b).

45-7p: Morning, I notice that I make some mistakes and cross out while writing and I worry again (NS: she writes "di" in place of "mi”).

45-7p: Morning, I feel as if the tongue was double (!).

45-8p: Morning, I slept like semi-conscious (!). Only at 7.00 in the morning a good sleep arrived, but I had to rise up.

45-8p: The tongue is always thick (!), double (maybe symbol of S45b, Mind, duality), rasping when it rubs the palate. I have noticed that the middle line is deeper and larger in the anterior half (K399b), on the contrary, in the posterior part it is totally absent.

45-8p: Night before sleep, I suddenly had diarrhoea (K609b), at first like rice water and then patently watery (K643a).

45-9p: Morning, also last night sleep was semi-conscious (!).

45-9p: Morning, another diarrhoea attack. This time it was burning as if I evacuated fire (K626a); this burning pain remains till now, I feel it stronger on the left side. I feel pain even in the abdomen (K560b).

45-9p: Night before going to bed, the bad temper persists, aggravated by a sense of impatience, speaking better, there is a subtle trembling from the knee downward (K1214a), this does not allow me to stay sitting on the sofa (K1213ab, K1401a), but it stops when I lie down (K1371b).

45-10p: This morning, I woke up spontaneously at 6.00 (S1743b).

45-10p: Morning, writing mistakes, misplacing letters (!).

45-10p: Morning, I have stomach pain, as if a hand would open and grip the stomach (K517b). Never happened before.

45-10p: Morning, the tongue is thick (!).

45-10p: Morning, diarrhoea (K609b) with burning stool (K626a), anal burning (K625a) and a burning sore in left perineum remained (K626b).

1. GT 257: All the time a great craving for bread, biscuit, soon after meals, late evening and early morning. (Hg).

2. GT 320: Pressure in the stomach after dinner (Hg). GT 326. Feeling of contraction in the stomach (after 6 h.) $(\mathrm{Ng})$. 
3. GT 904: Motions like trembling in the leg (after $\left.2 \frac{1}{1 / 2} \mathrm{~h}.\right)(\mathrm{Ng})$. GT 903: Shivering with cramps in the right thigh over the knee) (Ng).

4. GT 527: Urging to stool, with watery stool (Ng).

5. GT 545: Anal burning pain during stool (Ng). GT 483: Discharge of hot flatulence that burns like fire (Ng).

\section{Doubtful symptoms}

45-1p: It is as if a hand would grip my calf (K975a). I cannot press or massage the part, because pressure increases the pain.

45-2p: I feel the sole hot (K1013a) or rather, as if it would irradiate heat from within outward. I am very tired and annoyed to sit down to write because of a sensation of swelling behind the sternum (K455a-Oesophagus). I feel that something wants to rise up to the throat (K455a-rising sensation), but in vain.

45-3p: At noon I ate a mon-chéry [a chocolate with a cherry], I felt its taste when it arrived to the throat and not in the tongue (K78a).

45-4p: Now I am in the office, the lucidity, the power I had to help my friend now is going away.

45-5p: I woke up at 4 a.m. (K1255a), because of the image of my friend who has died.

45-6p: It is the first time I feel apparently calm, speaking better, I am without energy to face the anger of my daughter. I do not feel inside any interest (K54b) neither towards myself, nor the house, nor (beloved or not) people.

45-7p: I ate an ice-cream, but I could not finish it because of vomiting.

45-7p: I was going to type and felt dizziness.

45-8p: I feel the lips dry, so I have to moisten them, but I have no thirst because I have a lot of salivation.

45-9p: Very bad humour. My daughters are around me, but I would like to be alone (K12a), I do not want to do, say (K86a) or listen to anything.

45-10p: I am in the office, the secretary does not arrive, well, I can finally be alone. Very bad humour, I feel angry with the entire world (K62b), I feel empty, without enthusiasm and good humour, all seems unbearable, enormous, tiresome. This apathy is impregnating me so much... that it does not allow me to undertake anything.

\section{Prover 48 - IT48}

17 events, 29 symptoms, 7 concordant, 5 repeated - synthetic diary

48-1p: Afternoon, slight sensation of constriction in the chest (K828a).

48-2p: Morning, slight sensation of constriction in the chest (region of the heart) (K828a) with stitching pain on the front (K863b) and between the left shoulder-blade and the spine (K938b). Feeling of 
burning pain in the left arm (K1092a, 1093a), from the wrist (K1093a) to the bend of the elbow (pulse frequency: 66/min.). This sensation came also again later, inconstantly.

48-2p: Evening, sharp stitching pains appear in abdomen at regular intervals (K591b). Sensation of constriction in the head (K112a).

48-3P: Morning at 5.30, anxious waking from a dream (K1236a) (NS: dream of cutting the penis of a young patient of mine - she is a pediatrician).

48-3p: Morning, feeling of constriction (left side) starting from the nape of the neck and extending to the left vertex, eye and zygoma (K197a, forward). This sensation comes and goes at regular intervals for $2 \mathrm{~h}$.

48-5p: Morning, stitching pains appear: feeling as if the uterus would be pierced by a pointed tool (until 4 p.m.) (!). Sensation of constriction in the head (until 8 p.m.) (K112a).

48-5p: Afternoon, the stitching pains in the uterus (!) still continue, always at irregular intervals and a feeling appeared of burning pain in the left arm (K1093a).

48-6p: Morning, the burning pain appears in the left arm (K1093a), stitching pains in the uterus at irregular intervals and constriction of the head (left half) (K112a), these sensations continue the whole day.

48-7p: Morning, sensation of burning pain in the left arm (K1093a) and stitching pains in the uterus (!) at irregular intervals which persist the whole day.

48-8p: Morning, feeling of heaviness in the head (K124b) and state of anxiety (K4a) with heat and trembling in the whole body (!) (these symptoms lasted all day until 9.00 p.m.).

48-8p: Afternoon, slight sensation of burning pain in the left arm (K1093a).

48-9p: Morning, anxiety and trembling (!) with sensation as if something should happen (S120b). Slight headache (heaviness) (K124b).

48-10p: Sensation of burning pain in the left arm (K1093a) the whole day.

48-11p: Diarrhoeic stool (K609b) and rumbling (K600b).

48-12p: Diarrhoeic stool with gas (!).

48-12p: Afternoon, diarrhoeic stool with gas (!). Distended abdomen (K544b) and rumbling the whole day (K600b).

48-13p: Diarrhoeic stool with gas (!). Distended abdomen (K544b).

1. GT 686: Twitching in the region of the heart (after $1 / 2 \mathrm{~h}$.) (Ng)

2. GT 663: Stitching pains in the left pectoral muscle, extending to the shoulder blade (Ng). GT 668: Several strong stabbing pains under the right breast extending to the shoulder blade (after $1^{1 / 2} \mathrm{~h}$.) (Ng).

3. GT 740: In the inner side of the right wrist, an area of itching and burning, especially after rubbing (Hg).

4. GT 437: Stitching like a needle under the navel, deeply inside (after 2 h.) (Ng). 
5. GT 59: Pressure from the occiput forwards to the front, with feeling as if the eyes were closing, with heaviness (after $1 \mathrm{~h}$. ), ameliorates standing up (Ng).

6. GT 687: A sharp pain in the region of the heart, then anxiety with heat and perspiration on the face, that goes away quickly (Ng). GT 999: Rising of heat and anxiety with sweat, in the afternoon. (Ng).

7. GT 528: Diarrhoea with rumbling in the belly, without pain (after 2 h.) (Bthm).

\section{Doubtful symptoms}

48-2p: I noticed that on lying down for a nap, I could not sleep, I had the sensation of be rested enough.

\section{Some dreams in our HPT}

IT 6-1:2p-night: I remember the dream: I was at the cottage by the sea, with me there were only two cats (mine and my neighbour's) hunting birds. Since I was alone, I thought it was better to close the windows and doors for fear of robbers. This dream did not disturb me at all (new dream).

IT 6-4:5p-night: I dreamed of going to the hospital to meet the patients for my qualification exam; unfortunately they were very numerous (508). Then a professor suggested me a book to prepare better for this exam, but its price was very high: 850.000 lire (about 430 Euro), so I did not buy it. On waking up, I smiled due to the absurdity of the dream, at the same time I was very anxious.

IT 24-2p, night: Very intense and meaningful dream: "I am organizing a homeopathic meeting (NS: he is a teacher) in the large room of my parish, but the microphone does not work. People start to complain. I look for the priest, I enter in a simple house. In the bedroom, I suddenly see a tall man, about 60, with a very wide and broad forehead, serious expression, but lively eyes, with great attention to his own moral being. His tallness rendered him authoritative, but he was bent, round-shouldered. Saturn was his planet. I was afraid of disturbing his privacy, at the moment he was retiring to bed, but he had no doubts to go back working again for our meeting. Duty towards his neighbour was his fundamental precept. We come down together, as from a sanctuary on a hill. Going down the hill, a wooden stick rises up from the ground and hits him on the perineal area. I hold him up and we walk down slowly towards a little town. We pass through a little supermarket where the glances between the bystanders at the cashier evoke proposals for sexual encounters. Finally we arrive to the room where the man tries to adjust the microphone." In the dream, I was fascinated by the man's high moral and spiritual stature. The old man anyway risked falling down the hill and to damage precisely the genital parts with the sticks on the slope. I see the difficulty to integrate the voice of the low instincts with the high ideals of the will and the numerous ambivalences to face.

IT 24-4p-03.30:09.30: Sleep is deep $(\mathrm{K}, 1234)$ with high dreaming activity (half an hour after intake) (K,1241). I remember the dreams with more clearness and I understand some deep meanings just during the dream, that is, I dream and interpret myself during the dream itself (NR: during the first 3 nights he describes 3 different and very articulated dreams).

(GT 975,976,977: Many pleasant dreams at night; He dreams a lot; Many dreams during a good sleep)

IT 48-3p, night: I woke up with a feeling of anguish. I dreamt of visiting a child (I am a pediatrician) in his home because of a high fever for some days (40 degrees), resistant to anti-inflammatory drugs and antibiotics, the child suffers from a purulent ulcer of the glans. The mother suggests me cutting his penis because she does not want to see her child suffer. And so I did. The penis was in state of erection and was joined to the 
pubis by a piece of skin. The moment I cut it off, a state of anguish rises inside ... I search immediately for a phone to find a surgeon and to try to repair the damage I caused. All the telephones were busy and I could not speak with anyone.

IT 24-5-night: dream to take lesson of Tai-Chi-Chuan from a capable teacher of martial arts, who moved with armony and power.

IT 45: dream to see a cemetery and to pass through a tomb and reach the underground of a school (through some passages she arrives into the bathroom). In the same school and the same moment the Bishop comes to visit the school and the schoolchildren. She goes up to see the Bishop.

\section{New symptoms}

Roughly $2 / 3$ of the total symptoms obtained $(n=199)$ were already present in repertories, $\mathrm{K}$ or $\mathrm{S}$, whereas about $1 / 3$ of the symptoms were new (NS), i.e., symptoms not listed in K or S before this HPT was carried out. As a rule, they appeared only once/twice in one single volunteer, but sometimes they were reported by 2 volunteers (crossed-symptoms) or appeared as repeated symptoms, (3 times or more in 1 volunteer in at least 2 different days).

We chose to count the symptoms extracted from the sentences in the volunteer's journal in a more restricted, synthetic, however more qualified manner than the usual custom to get many symptoms from a single sensation. For example, from a complex expression, such as stitching headache, aggravated by motion • , one can extract 1 to 4 symptoms (head-pain, head-pain-stitching, head-pain-stitching-motion-agg, head-painmotion-agg), if all the specifications of the symptom are considered. However, we preferred to count only a symptom from a single sensation even if described with modalities. Perhaps this decision was too rigid and the broadening of symptoms through the modalities described by the volunteers could be reliable criteria to distinguish between verum and placebo symptoms. However, there are no studies on this regard and to be overly cautious, as we were, is a better way to avoid bias.

Table 2: New symptoms in the 2000 trial. Between brackets the code number of volunteers. $\mathrm{R}=$ repeated symptom. 
1. Mind, Comprehension, easy (IT24)

2. Mind, Delusions, tongue, double (IT45)

3. Mind, Delusions, upright (IT24)

4. Mind, Fear, heart, diseases of the heart- Mind, Anxiety, heart, about his (IT24)

5. Mind, Industrious, morning, on waking (IT39R)

6. Mind, Mistakes, writing (IT24R, P45R)

7. Mind, Mistakes, writing, omitting, words (IT45)

8. Mind, Mistakes, writing, thoughts, from fast (IT45)

9. Mind, Mistakes, writing transposing letters (IT24)

10. Vertigo, Rising, agg. (IT42)

11. Head, Congestion, Meninges (IT24)

12. Head, Congestion, Occiput (IT24)

13. Vision, Colours, bright, spots (in the dark) (IT42)

14. Mouth, Bleeding, Gums, cleaning them, when (IT42)

15. Mouth, Crawling, Lips, around (IT42)

16. Mouth, Roughness, tongue (IT45R)

17. Mouth, Thick, sensation as if, tongue was (IT45R)

18. Face, Chapped, lips (IT42)
19. Face, Wrinkled, Forehead (IT6)

20. Neck, Perspiration (IT21, IT45)

21. Stomach, Appetite increased, night (IT6);

22.Stomach, Appetite increased, accompanied by sleepiness (IT6).

23. Rectum, flatus, diarrhoea, during (IT48R)

24. Chest, Itching, Mammae, Nipples (IT42)

25. Chest, Congestion, Heart (IT24)

26. Male, Ulcer, Glans (IT21).

27. Female, Pain, Uterus, stitching (IT48R)

28. Skin, Itching, wandering (IT39)

29. Skin, Itching, ameliorated by cold water (IT21)

30. Skin, Prickling (IT39)

31. Sleep, Semi-conscious (IT45R)

32. Dreams, Penis, cut off (IT48)

33. Dreams, Teacher, of spiritual (IT24, IT45)

34. Generalities, Air, draft, agg. (IT24R)

35. Generalities, Food, desire for ice-cream (IT6, IT39).

36. Generalities, Heat, anxiety, during (IT48)

37. Generalities, Trembling, externally, anxiety, with (IT48)

\section{Key symptoms in both trials.}

The comparison between the symptoms in Hartlaub \& Trinks' first and our second trial allows confirming the clinical indications arising from the former, whereas the new symptoms permit completing the picture of the remedy (Table 3). Some symptoms of the first trial were not found in ours, possibly because the number of 
volunteers was larger in the former. Notably, our trial failed to report symptoms corresponding to pain in the lower limbs. Conversely, in our study dreams were more interesting and painted a colourful picture of the symbols associated with the saturnine remedy Plumbum metallicum.

Table 3: Key-symptoms in both HPTs

\section{Key symptoms}

Anxiety with fear for the heart and tendency to hypertension, with increased perspiration (especially on the face and the neck), heat and trembling, dryness of the mouth and the palate with thick saliva and pallor on the face.

Hyperactivity or alternation of hyperactivity with laziness, with a sensation of alertness, "as if something could happen". Mistakes in writing because ideas are quicker than writing.

Sensation of dilatation, congestion and bursting: head, meninges, heart.

Stitching pains in the chest, stomach, back and uterus.

Sour metallic taste in the mouth.

Sensation of swelling or foreign body in the throat, that moves up and down on swallowing.

Sour regurgitation and stitching pains in the chest and between the shoulder-blades (gastroesophageal reflux?).

Appetite increased in the evening/night before sleeping, with desire to eat dry things (biscuits, bread) and ice-cream.

Contractions everywhere, especially in the stomach as from a gripping hand, in the head, heart, spermatic cord, abdomen and extremities.

Motions and intestinal noises, flatulence.

Diarrhoea, watery, with fermentation and rumbling in the abdomen, anal burning during stool or flatus.

Sensation of pin-pricks in the skin.

Ulcers and excoriation of the penis and scrotum.

Weakness in the lower limbs and feet with difficulty to exercise, formication and numbness from the knees to the feet, tearing or stitching pains in the knee, cramps in the soles of the feet.

Sleep disturbed, semiconscious, awaking at 4.00, early waking at 6.00, with high dreaming activity.

Skin and hair oily; burning, itching and stinging in the skin, ameliorated by scratching.

Sensitiveness to cold air and drafts of air.

\section{Appendix: synthesis of the 1828 HPT}

(between brackets the number of the original reference, in bold important symptoms in the trial) 
1. Anxiety (6), anguish with sighing (8), anxiety with epigastric pains (335), with difficult respiration (628), with heart pains and heat on the face $(687,688)$, fear with heat and perspiration (999), frightful dreams $(978,980)$

2. Ennui, taciturn, morose (14-18)

3. Laziness, aversion to work (19-21)

4. Cheerful, good humour $(35,36)$

5. Extremely active in his work (37)

6. Occipital and frontal heaviness or pressure (54-60)

7. Congestion beneath the skull (meninges) (58)

8. Tearing pains in the head (62-68)

9. Heat in the head, rising from the belly, with redness on the face $(67,78,79)$

10. Stitching pains in the parietal, temporal and frontal bones (69-77)

11. Oily hair (80)

12. Falling of hair from the brows and moustache $(81,82)$

13. Tearing, stitching and burning pains in the eyes (96-98)

14. Twitching in the lids and eyes $(87,104)$

15. Flushes of blood in the eyes (99)

16. Foggy vision (109-111)

17. Heat and redness of the face, with perspiration on the upper part of the body (147)

18. Frequent itching on the face, eyes, ears and nose, scratching ameliorates $(83-84,121,148,603)$

19. Stitching in the face (149)

20. Paleness of the face and gums $(157,167)$

21. Greasy skin in the face (150)

22. Burning in the mouth and tongue $(176,180,182)$

23. Difficult swallowing in the throat and oesophagus, as from a strain, stretch or strangling, constriction $(189,192,203)$

24. Sensation of swelling or foreign body in the throat, that moves up and down on swallowing with pain in the right shoulder-blade (191,192,195-199)

25. Dry mouth and throat $(207,211)$ 
26. Taste like sulphur and sour taste in the mouth (214)

27. Abundant mucous in the mouth in the morning $(216,218)$

28. Viscid saliva with sweetish taste and dryness of the posterior part of the fauces $(221,225)$

29. Empty and incomplete eructation $(231,237)$

30. Strong appetite after eating and before going to sleep (253-256)

31. Strong desire for bread and biscuits (257)

32. Intense thirst (259,262-4)

33. Intense nausea passing soon (271)

34. Retching (274)

35. Sour eructation and regurgitation $(281,282)$

36. Grip or contraction of the stomach $(320,326)$

37. Grip in the stomach with heaviness in the occiput (323)

38. Burning in the stomach (332)

39. Stitching and pressing pains rising upwards with anxiety (334-337)

40. Pains in the right or left hypochondria, in the liver and spleen (339-349)

41. Pains and pinches in the abdomen and the region of the navel $(352,424,426-429)$

42. Pains in the inguinal region (376)

43. Sensation of contraction and obstructed flatulence in the lower abdomen $(378,384)$

44. Stitching pains in the abdomen (437-440)

45. Parestesia, as if sitting in cold water up to the belly and then heat in the abdomen (444)

46. Stitches and stretches in the flanks, contractions $(458-461,553)$

47. Movements and intestinal noises, flatulence (464-472, 476,479)

48. Flatus burning as from fire (484)

49. Constipation $(487,488,503,508,515)$

50. Diarrhoea with rumbling, thin liquid stool (524-528)

51. Ineffectual urging to stool (537-541)

52. Burning pain in the rectum during stool (545)

53. Drawing pain in the anus, upwards (552) 
54. Retention of urine and burning pain in the urethra (559)

55. Twitching in the spermatic cords (578)

56. Excoriation of the scrotum and thighs (585)

57. Pollutions during sleep, without erections $(590,592)$

58. Erections painful (592)

59. Pressing pains in the chest and the lower part of the sternum, as if in a vise $(643,653,654,656)$

60. Pressing pain in the left side of the chest fore and behind that comes and goes $(657,658)$

61. Chest pain in front and between the scapulae, aggravated from breathing, laughing and lying, extending to the left arm (659)

62. Stitches in the chest extending to the scapulae $(663,668)$

63. Stitching pains in the left and right side of the chest, or near the sternum, aggravated from inspiration, ameliorated from massage $(661,662,664-667,669-674,676,678)$

64. Stitches in and under the breast $(679,680,682-684)$

65. Twitching in the region of the heart (686)

66. Stitches in the region of the heart (687)

67. Palpitations (693)

68. Drawing and constricting pains in the nape and shoulder-blades (698-703)

69. Stitches and burning pains in and between the shoulder-blades (704-708)

70. Stitches in the back, standing or sitting, ameliorated from massage (709-711)

71. Pressing pain between sacrum and pubis (712)

72. Stitches in the right axilla (717-720)

73. Painful strains, contractions or tears in the arm, elbow, hand or fingers (724-731,734,736738,741-743,748,749)

74. Itching and burning in the internal part of the wrist (740)

75. Itching between the fingers of the hand (745-747)

76. Paralysing pains in the lower limb on ascending stairs (752)

77. Numbness from the knee to the foot, on the foot and toes $(754,775,776,783)$

78. Jerking and fine contractions in the thigh (755-758)

79. Dull pains and intense stitches in the knee (760,762-764) 
80. Tears or contractions in the leg, tibia, heel and toes $(766,768,771,780-782)$

81. Painful sensation as from a sprain in the ankle (772)

82. Cramps in the sole of the feet (774)

83. Skin sensitive to the air (803)

84. Itching in the region of the eruptions, that ameliorates by scratching $(813,603,713)$

85. Itching eruptions in the fingers and the wrist (818)

86. Heaviness and weakness of legs and feet (827-831)

87. Weakness of lower limbs and knees on ascending stairs or after motion $(832,833,835,838,840)$

88. Great exhaustion with pulsation of the arteries of the body (856-858)

89. Muscle jerking of the thigh and leg with trembling $(903,904)$

90. Yawning and sleepiness, early in the evening (955-963)

91. Nostalgic thoughts in the evening or during dreams $(965,981)$

92. Difficult falling asleep (966)

93. Many dreams (975-977)

94. Fearful dreams $(978,980)$

95. Dreams of stealing fruit in the garden (979)

96. Dreams of falling (980)

97. Voluptuous dreams (982)

98. Talking during sleep (983-984)

99. Coldness aggravated in open air (991,993-994)

100. Flushes of heat all over the body with perspiration and fear and muscular weakness (997,999-1000,1003-1004)

101. Pulsation in the arteries (1023)

\section{References}

[1] Signorini A, Lubrano A, Manuele G, Fagone G, Vittorini C, Boso F, Vianello P, Rebuffi A, Frongia T, Rocco V, Pichler C. Classical and new proving methodology: Provings of Plumbum metallicum and Piper methysticum and comparison with a classical proving of Plumbum metallicum. Homeopathy. 2005; 94: 164174. 
[2] Hartlaub CGC and Trinks CF. Reine Arzneimittellehre, Erster Band. F.A. Brockhaus, Leipzig: Documentation \& Library, DHU— Deutsche Homöopathie-Union GmbH \& Co KG, Ottostr. 24, 76227 Karlsrhue, Germany. Available at http://linkinghub.elsevier.com/retrieve/pii/S1475491605000202

[3] Kent JT. Repertory of the Homeopathic Materia Medica (reprint edition of sixth american edition). New Delhi(India): B. Jain Publishers Pvt. Ltd., 1990.

[4] Schroyens F. Synthesis Repertorium Homeopathicum Syntheticum, Edition 9.1. Assesse (Belgium), Homeopathic Book Publisher, 2004

[5] Schroyens F. Synthesis Repertorium Homeopathicum Syntheticum, Edition 8. Assesse (Belgium), Homeopathic Book Publisher, 2001

\title{
Experimentação patogenética homeopática de plumbum metallicum: a experimentação complete realizada no ano 2000 , com a síntese daquela original, realizada em 1828.
}

\begin{abstract}
RESUMO
Introdução: em artigo anterior, foi reportada a análise estatística e outras distribuições de dados de uma experimentação patogenética homeopática de Plumbum metallicum $30 \mathrm{cH}$. Porém, nessa ocasião, não reportamos os resultados da materia médica pura, isto é, a totalidade dos sintomas induzidos pela substância testada, nos voluntários saudáveis. Objetivos: comunicar a comunidade homeopática a lista completa de sintomas coletados na experimentação de Plumbum metalicum. Métodos: os métodos de coleta e seleção de sintomas foram reportados em artigo anterior. Em síntese, excluí-se todos os sintomas comuns previamente apresentados pelos voluntários e selecionou-se aqueles que eram realmente desconhecidos, nunca vistos, incomuns para o experimentador. Ênfase especial foi dada a sintomas novos, assim como a sonhos incomuns e recorrentes. Resultados: os sintomas são reportados na ordem cronológicas em que foram aparecendo nos voluntários. 37 novos sintomas foram encontrados, e foram usados para atualizar o Repertório Homeopático. Também foi incluída uma síntese da experimentação originalmente realizada em 1828, a fim de disponibilizar uma matéria médica experimental completa. Conclusões: Esta nova experimentação, além de ampliar a imagem patogenética de Plb, também permitiu dar um novo e mais profundo significado para alguns dos sintomas relatados na experimentação original (ansiedade, atividade, depressão, lentidão, problemas gastroesofágicos, colite). Até onde sabemos, não existe uma publicação com revisão por pares dedicada à publicação de experimentações patogenéticas homeopáticas. Por esta razão, pesquisadores são compelidos a publicar seus resultados como edições privadas. Isto resulta num controle precário da qualidade dessas publicações e na falta de padronização sobre como apresentar tais resultados.
\end{abstract}

Palavras-Chave: Experimentação patogenética homeopática; Plumbum metallicu; re-experimentação; Indicações clínicas

\section{Experimentacion patogenética homeopática de plumbum metallicum: experimentación completa realizada em el año 2000 juntamente com la sintesis de la original realizada em 1828}

\section{RESUMEN}

Introducción: Em um articulo anterior fue reportado el análisis estadistico y otras disteibuciones de datos de uma experimentacion patogenética homeopática de Plumbum metallicum 30cH. Pero em esta ocación no 
reportamos los resultados de la Materia médica pura, esto es, la totalidad de síntomas induzidos por la sustancia testada en voluntarios sanos. Objetivos: comunicar a la comunidad homeopática la lista completa de síntomas colectados em la experimentación de Plumbum metallicum. Métodos: los metodos de coleta y selección de sintomas foram reportados en artículo anterior. En síntese, foram excluidos todos los sintomas comunes previamente presentados por los voluntários y seleccionamos aquellos no conocidos, incomunes para el experimentador. Fue dado un énfasis especial a los sintomas nuevos y a los sueños incomunes y recurrentes. Resultados: los sintomas son reportados en el orden cronológico en que fueron apareciendo en los voluntarios. 37 nuevos sintomas fueron descritos y permitieron actualizar el Repertório Homeopático. También fue incluida uma síntesis de la experimentación originalmente realizada em 1828, com el fin de disponibilizar uma materia médica experimental completa. Conclusiones: Esta nueva experimentación, ademas de ampliar la imagen patogenetica Plumbum metallicum, también permitió dar un nuebo y mas profundo significado para algunos de los síntomas relatados em la experimentación original (ansiedad, actividade, depresión, problemas gastroesofágicos, colitis). Hasta donde sabemos, no existe uma publicación com revisión por pares, dedicada a la publicación de experimentaciones homeopáticas patogenéticas homeopáticas. Por esta razón investigadores son impelidos a publicar sus resultados como ediciones privadas. Estoresulta em um control precario de calidad de esas publicaciones y em la falta de padronización sobre como presentar tales resultados.

Palabras-llave: experimentación patogenética homeopática, Plumbum Metallicum, re-experimentación, indicaciones clínicas.

\section{(c)) EY-NC-ND Licensed to GIRI}

Support: authors declare that this study received no funding

Conflict of interest: authors declare there is no conflict of interest

Received: 09 November 2011; Revised: 12 March 2011; Published: 30 March 2011.

Correspondence author: Andrea Maria Signorini, s.andrea.ver777@gmail.com

How to cite this article: Signorini AM, Pichler C. Homeopathic pathogenetic trial of Plumbum metallicum: the complete 2000 trial with a synthesis of the original 1828 trial. Int J High Dilution Res [online]. 2011 [cited YYYY Month dd]; 10(34):15-36. Available from http://www.feg.unesp.br/ ojs/index.php/ijhdr/article/view/416/457 